\title{
Comparison of pain scores between patients undergoing panretinal photocoagulation using navigated or pattern scan laser systems
}

\author{
Comparação de graduação de dor entre os pacientes submetidos à panfotocoagulação \\ usando sistemas de laser navegado ou de padrão de varredura
}

Umit Ubeyt Inan ${ }^{1}$, Onur Polat ${ }^{2}$, Sibel Inan ${ }^{1}$, Safiye Yigit ${ }^{1}$, Zeki Baysal ${ }^{1}$

\begin{abstract}
Purpose: To compare the pain responses of patients with proliferative diabetic retinopathy (PDR) undergoing panretinal photocoagulation (PRP) using either pattern scan laser (PASCAL) or navigated laser photocoagulation (NAVILAS).

Methods: Patients diagnosed with PDR were randomly assigned to undergo either PASCAL or NAVILAS photocoagulation treatment. PRP was performed using the multi-shot mode with a spot size of $200-400 \mu \mathrm{m}$ and a pulse duration of $30 \mathrm{~ms}$ to obtain a white-grayish spot on the retina. Parameters were identical in both procedures. After 30 min of PRP application, patients were asked to verbally describe their pain perception as either "none," "mild," "moderate," "severe," or "very severe" using a verbal rating scale (VRS) and visual analog scale (VAS) by indicating a score from " 0 " to " 10 ," representing the severity of pain from "no pain" to "severe pain."

Results: A total of 60 eyes of 60 patients (20 females and 40 males) diagnosed with PDR were treated. The mean age of patients was $62.22 \pm 9.19$ years, and the mean diabetes duration was $195.47 \pm 94.54$ months. The mean number of laser spots delivered during PRP was $389.47 \pm 71.52$ in the NAVILAS group and $392.70 \pm 54.33$ in the PASCAL group ( $p=0.57$ ). The difference in pain responses between patients in the NAVILAS and PASCAL groups was significant with regard to the mean VRS $(1.10 \pm 0.67$ and $1.47 \pm 0.69$, respectively; $p=0.042)$ and mean VAS $(2.13 \pm 1.17$ and $2.97 \pm 1.35$, respectively; $p=0.034)$ scores.

Conclusions: Pain responses in patients undergoing PRP with a 30-ms pulse duration were significantly milder in the NAVILAS group than in the PASCAL group.
\end{abstract}

Keywords: Diabetic retinopathy; Equipment design; Laser coagulation; Pain measurement

\section{RESUMO}

Objetivo: Comparar as respostas de dor de pacientes com retinopatia diabética proliferativa (PDR) submetidos à panfotocoagulação retiniana (PRP) usando laser de padrão de varredura (PASCAL) ou fotocoagulação navegada a laser (NAVILAS).

Métodos: Pacientes com diagnóstico de PDR foram aleatoriamente designados para submeter-se ao tratamento de fotocoagulação com PASCAL ou NAVILAS. A PRP foi realizada no modo "multi-shot" com diâmetro do laser de 200-400 um e duração do pulso de $30 \mathrm{~ms}$, utilizados para se obter uma mancha branca-acinzentada na retina. Os parâmetros foram idênticos em ambos os procedimentos. Após 30 minutos da PRP, os pacientes foram solicitados a descrever verbalmente a sua percepção da dor como quer "nenhuma," "leve," "moderada," "intensa" ou "dor muito intensa" por meio de uma escala de avaliação verbal (VRS) e também por meio de uma escala visual analógica (VAS), indicando uma pontuação de " 0 " a " 10 " representando a intensidade da dor de "nenhuma dor" a "dor intensa."

Resultados: Um total de 60 olhos de 60 pacientes (20 mulheres e 40 homens) com diagnóstico de PDR foram tratados. A média de idade dos pacientes foi de 62,22 $\pm 9,19$ anos e a média de duração da diabete foi 195.47 $\pm 94,54$ meses. O número médio de pulsos de laser emitidos durante a PRP foi 389,47 $\pm 71,52$ no grupo NAVILAS e 392,70 $\pm 54,33$ no grupo PASCAL $(p=0,57)$. A diferença nas respostas de dor entre os pacientes nos grupos NAVILAS e PASCAL foi significativa em relação às médias de VRS $(1,10 \pm 0,67$ e 1,47 $\pm 0,69 ; p=0,042)$ e VAS $(2,13 \pm 1,17$ e 2,97 $\pm 1,35 ; p=0,034)$.

Conclusões: As respostas de dor em pacientes submetidos à PRP com pulsos de $30 \mathrm{~ms}$ de duração foram significativamente menores nos pacientes do grupo NAVILAS em relação ao grupo PASCAL.

Descritores: Retinopatia diabética; Desenho de equipamento; Fotocoagulação alaser; Medição da dor

\section{INTRODUCTION}

Diabetic retinopathy is the leading cause of vision loss in the elderly ${ }^{(1)}$. Almost $95 \%$ of diabetes-related visual impairment, however, is preventable by early diagnosis and photocoagulation therapy ${ }^{(2)}$. A number of multi-center trials have consistently demonstrated the benefits of photocoagulation in high-risk patients with proliferative diabetic retinopathy $(\mathrm{PDR})^{(3,4)}$.

Panretinal photocoagulation (PRP) is painful, and a substantial number of patients are therefore undertreated and at an increased risk of developing blindness $s^{(5)}$. Compared with the widely used conventional laser, new technologies provide more comfortable, less harmful and time-saving treatments because of sub-threshold and multi-shot laser photo coagulators ${ }^{(6,7)}$.

The pattern scan laser (PASCAL; Opti-Medica Corp., Santa Clara, California, USA) is a new generation semi-automatic and multi-shot photocoagulator, which uses either a single or predetermined pattern array with pulse durations as short as 10-30 ms $\mathrm{s}^{(8,9)}$. Navigated laser photocoagulation (NAVILAS; OD-OS GmbH, Teltow, Germany) is another novel computer-based double-frequency ND:YAG laser photocoagulation system (532 nm), which, apart from offering retina navigation, has similar technical specifications as PASCAL (single or prede-

${ }^{1}$ Department of Ophthalmology, Faculty of Medicine, Afyon Kocatepe University, Afyonkarahisar, Turkey.

2 Ophthalmology Clinic, Afyonkarahisar State Hospital, Afyonkarahisar, Turkey.

Funding: No specific financial support was available for this study.

Disclosure of potential conflicts of interest: None of the authors have any potential conflict of interest to disclose.

Corresponding author: Onur Polat. Ophthalmology Clinic. Afyonkarahisar State Hospital, Afyonkarahisar - 03200 - Turkey - E-mail: dr_onurpolatt@hotmail.com 
termined pattern array, 10-30-ms pulse duration) $)^{(10,11)}$. Compared with conventional lasers, both modalities use shorter laser pulses, cause relatively less thermal damage to adjacent retinal tissues and are therefore possible to produce relatively less painful photocoagulation. Whether one of these new laser platforms produce less pain than the other during the panretinal photocoagulation is not extensively investigated.

In this study, we sought to compare pain responses in patients undergoing PRP with either PASCAL or NAVILAS for PDR.

\section{METHODS}

\section{Patients}

Among patients presenting with visual complaints between June and September 2014, those diagnosed with PDR were enrolled in the study. Patients were randomly assigned to receive either NAVILAS or PASCAL photocoagulation therapy. Ethical committee approval and informed consent from patients were obtained, and the study adhered to the tenets of the Helsinki Declaration.

The inclusion criteria were as follows: being older than 18-years, having a diagnosis of diabetes mellitus type 1 or 2 , and presenting with a high risk of PDR. A high risk of PDR was defined as neovascularization of the optic disc, neovascularization associated with vitreous or preretinal hemorrhages (NVEs), or neovascularization greater than one-half of the disk area in size accompanying vitreous or preretinal hemorrhage regardless of NVE location.

Patients with a low risk of PDR, those with poor compliance, and pregnant women were excluded. Additionally, patients with a history of focal/grid photocoagulation or PRP, orbital trauma or surgery; those presenting with inflammatory signs; those with significantly increased corneal or lens thickness; and those with vitreous hemorrhage were also excluded.

All patients were subject to the following assessments: slit-lamp biomicroscopy, intraocular pressure measurement with Goldmann applanation tonometry, fundus fluorescein angiography, and ophthalmologic examination including fundus assessment.

\section{LASER APPLICATION}

Patients were randomly assigned to either the PASCAL (30 patients) or NAVILAS (30 patients) groups. All patients were treated by the same surgeon and underwent a single PRP session. Treatments were performed under topical anesthesia.

The spot size (200-400 $\mu \mathrm{m}$ ) and pulse duration (30 ms) used to obtain a white-grayish spot on the retina were identical in both procedures. To objectively compare pain responses, PRP was used in the multi-shot mode and was applied within similar retinal areas, and the total number of spots delivered was equivalent.

\section{Pain perception}

After 30 min of PRP application, patients were asked to verbally describe their pain perception as either "none," "mild", "moderate", "severe", or "very severe" through a verbal rating scale (VRS). Additionally, they were asked to specify the severity of pain through a visual analog scale (VAS) by indicating a score from " 0 " to " 10 ," representing the severity of pain from "no pain" to "severe pain."

\section{Statistical analysis}

Statistical analyses were performed using the SPSS (Statistical Package for Social Sciences Inc., Chicago, IL, ABD) version 17.0 software. Data distribution was assessed by the Kolmogorov-Smirnov test. Comparisons were performed using the Mann-Whitney $U$ test and $t$-test for independent samples.

\section{RESULTS}

A total of 60 eyes of 60 patients (20 females and 40 males) diagnosed with PDR were treated. The mean age of patients was 62.22 \pm 9.19 years, and the mean duration of diabetes was $195.47 \pm 94.54$ months. Patient demographics are presented in table 1. There were no significantly differences between the groups in terms of mean age, gender, and mean diabetes duration.

The mean number of laser spots delivered during PRP was $389.47 \pm$ 71.52 in the NAVILAS group and $392.70 \pm 54.33$ in the PASCAL group. The difference was not significant $(p=0.57)$.

The difference in pain response between patients in the NAVILAS and PASCAL groups was significant with regard to both mean VRS $(1.10 \pm 0.67$ vs. $1.47 \pm 0.69$, respectively; $p=0.042)$ and mean VAS $(2.13 \pm 1.17$ vs. $2.97 \pm 1.35$, respectively; $p=0.034$ ) scores (Table 2$)$.

While no patients in the PASCAL group reported "no pain" in the VRS assessment, four (13.3\%) in the NAVILAS group reported "no pain" associated with PRP application. A total of 11 of 30 patients reported experiencing moderate or severe pain during PASCAL laser treatment compared with 6 of 30 treated with the NAVILAS laser. None of the patients in either groups reported "very severe pain." Patient distribution according to VRS is presented in figure 1.

\section{DISCUSSION}

The advent of photocoagulation in 1967 was a critical step in the treatment of diabetic retinopathy and maculopathy ${ }^{(12)}$. PRP treatment may cause considerable pain and discomfort in some patients and

Table 1. Demographic characteristics of study individuals

\begin{tabular}{lccc}
\hline & NAVILAS & PASCAL & P \\
\hline Gender (F/M) & $8 / 22$ & $12 / 18$ & $0.270^{*}$ \\
Age (mean \pm SD) & $63.3 \pm 9.4$ & $61.1 \pm 9.1$ & $0.351^{* *}$ \\
$\begin{array}{l}\text { Duration of diabetic disease } \\
\text { (mean } \pm \text { SD) }\end{array}$ & $206.8 \pm 101.1$ & $184.1 \pm 87.8$ & $0.480^{* *}$ \\
\hline
\end{tabular}

${ }^{*}=$ chi-square test $;{ }^{* *}=$ independent $t$-test.

Table 2. Pain scores associated with NAVILAS laser and PASCAL laser treatments

\begin{tabular}{lccc}
\hline & NAVILAS & PASCAL & P \\
\hline Verbal score & $1.10 \pm 0.67$ & $1.47 \pm 0.69$ & 0.042 \\
VAS & $2.13 \pm 1.17$ & $2.97 \pm 1.35$ & 0.034 \\
\hline
\end{tabular}

VAS= visual analog scale; $\mathrm{p}=$ Mann-Whitney $U$ test.

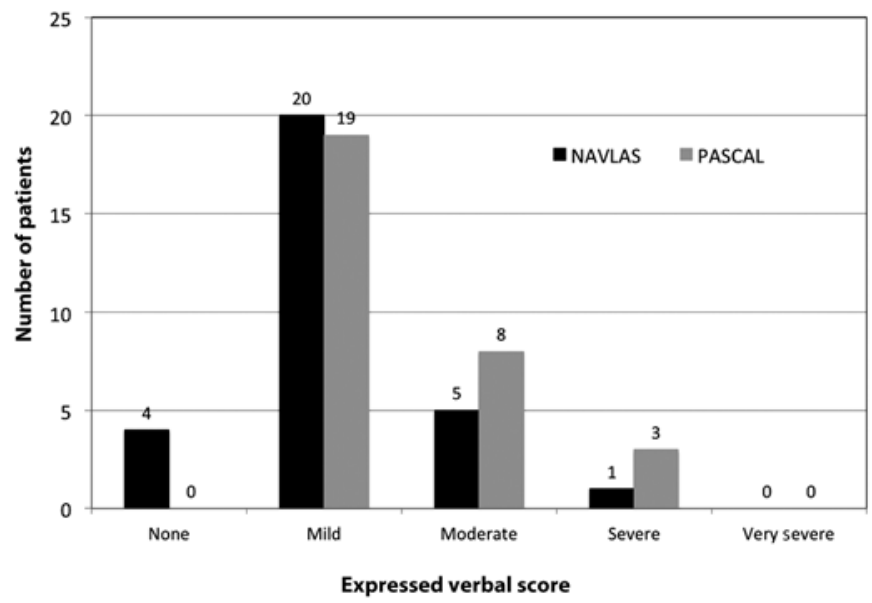

Figure 1. Number of patients subject to photocoagulation treatment by the two laser systems (PASCAL or NAVILAS) according to expressed verbal score. 
may consequently yield reluctance to continuing treatment sessions, thus leading to visual deterioration. By changing laser parameters, however, it may be possible to improve comfort and reduce pain ${ }^{(13)}$. In the current study, we found that patients undergoing PRP treatment with the NAVILAS system experienced significantly less pain than those treated with the PASCAL system with a pulse duration of $30 \mathrm{~ms}$.

The Diabetic Retinopathy and Early Treatment Diabetic Retinopathy studies, using a single-shot conventional laser device, established the minimum laser power levels in PRP treatment with a spot size of 200-500 mm and a pulse duration of 100-200 ms ${ }^{(14,15)}$. Novel laser treatment systems, however, use the multi-shot mode with short pulse duration, thereby providing shorter, less demanding, and less painful treatment sessions ${ }^{(16)}$. Furthermore, studies have shown that a short pulse duration does not negatively influence PRP treatment efficacy ${ }^{(16-18)}$.

Targeting the retinal pigment epithelium while preserving adjacent photoreceptors through micro-air bubble formation formed around melanosomes is a novel target therapy modality of laser photocoagulation. The critical threshold between thermal and mechanical damage is $50 \mathrm{~ms}^{(19-21)}$. Owing to the use of shorter pulses, novel laser therapy techniques cause only mechanical but not thermal damage, limiting the damage to the retinal pigment epithelium and preserving the inner retinal layers and sensory-rich chorioretinal tissues ${ }^{(17)}$. Consequently, patients usually report less pain, most probably because retinal sensitivity is better preserved as compared with pain in conservative approaches ${ }^{(9,17)}$. Recent studies have consistently shown that patients treated with either the PASCAL or NAVILAS laser system modalities experienced less pain as compared with those

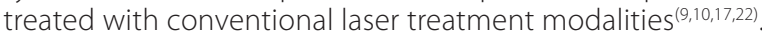

The reason why patients treated with the NAVILAS system experience less pain than those treated with the PASCAL system may in part be attributed to the fact that the former uses infrared light instead of the bright slit-lamp light used in the latter. Infrared light is known to cause less photostimulation ${ }^{(16)}$.

Additionally, both conventional and PASCAL treatment systems require the tilting and moving of a contact lens for treating the peripheral retina, which may cause discomfort ${ }^{(23)}$. The NAVILAS system, on the contrary, uses a specifically designed contact lens and does not require tilting of the lens for the examination and treatment of the retinal periphery ${ }^{(24)}$. The tilting of the lens is also related to laser focusing, significantly influencing spot size and energy density at the level of the retina ${ }^{(23)}$. Focusing is performed by moving the slit lamp closer or further away from the eye in the PASCAL laser system, where laser and image foci may not be identical. On the other hand, the NAVILAS laser system enables the documentation of focus settings adjusted prior to treatment to achieve a clear focused retinal image and focused laser beam ${ }^{(25)}$. As a recent study revealed, laser spots delivered during NAVILAS photocoagulation are more accurate than those delivered using the PASCAL system. Thus, inadvertent laser application is minimized, collateral damage within the retina is decreased, and the preservation of retinal sensitivity is improved, eventually resulting in more comfort and less pain (24).

Response to pain among individuals may vary depending on factors such as culture, gender, threshold of pain, degree of fundus pigmentation, and history of previous laser treatment ${ }^{(17,26)}$. None of the patients included in this study had a previous history of laser treatment. Additionally, randomization provided a more objective assessment of pain. Nevertheless, these factors may still, in part, account for the difference observed in the perception of pain.

Our review of literature identified two additional trials, both conducted by Chablani et al. ${ }^{(16,24)}$, comparing differences in the perception of pain between patients with PDR undergoing NAVILAS or PASCAL photocoagulation. In both studies, a pulse duration of 100 ms was used, and it was found that treatment-related pain was significantly milder following NAVILAS than following PASCAL photocoagulation (24). In the current study, however, we found that treatment with a pulse duration of $30 \mathrm{~ms}$ also resulted in milder pain in patients treated with
NAVILAS compared with those treated with PASCAL. This issue has rarely been investigated and merits further consideration with long-term follow-up studies on larger groups.

While the relatively small number of spots delivered may appear to be a limitation, the main purpose of the study was to compare pain responses and not treatment efficacy. In the Diabetic Retinopathy Clinical Research Network (DRCR.net) clinical trial, no clinical difference was found when comparing PRP in one session versus that in four sessions in terms of pain perception ${ }^{(27)}$. One limitation was the small sample size. Additionally, we followed all patients and performed the second and third treatment sessions after one week at the latest and eventually completed PRP treatments within one month at the latest.

To conclude, the new, navigated laser approach provided by the NAVILAS system enables the delivery of multiple laser spots in a relatively shorter time with improved accuracy and efficacy, significantly reducing pain and improving patient compliance.

\section{REFERENCES}

1. Congdom NG, Frieman DS, Lietman T. Important causes of visual impairment in the world today. JAMA. 2003;290(15):2057-60.

2. Ferris FL III. How effective are treatments for diabetic retinopathy? JAMA. 1993;269(10): 1290-1.

3. Diabetic Retinopathy Study Research Group. Preliminary report on effects of photocoagulation therapy. Am J Ophthalmol. 1976;81(4):383-96.

4. Photocoagulation treatment of proliferative diabetic retinopathy. Clinical application of Diabetic Retinopathy Study (DRS) findings, DRS Report Number 8. Diabetic Retinopathy Study Research Group. Ophthalmology. 1981;88(7):583-600.

5. Lucena CR, Ramos Filho JA, Messias AM, Silva JA, Almeida FP, Scott IU, et al. Panretinal photocoagulation versus intravitreal injection retreatment pain in high-risk proliferative diabetic retinopathy. Arq Bras Oftalmol. 2013;76(1):18-20.

6. Nakamura Y, Mitamura Y, Ogata K, Arai M, Takatsuna Y, Yamamoto S. Functional and morphological changes of macula after subthreshold micropulse diode laser photocoagulation for diabetic macular oedema. Eye (Lond). 2010;24(5):784-8.

7. Bolz M, Kriechbaum K, Simader C, Deak G, Lammer J, Treu C, et al. In vivo retinal morphology after grid laser treatment in diabetic macular edema. Ophthalmology. 2010;117(3):538-44

8. Jain A, Blumenkranz MS, Paulus Y, Wiltberger MV, Andersen DE, Huie $P$, et al. Effect of pulse duration on size and character of the lesion in retinal photocoagulation. Arch Ophthalmol. 2008;126(1):78-85.

9. Blumenkranz MS, Yellachich D, Andersen DE, Wiltberger MV, Mordaunt D, Marcellino $\mathrm{GR}$, et al. Semiautomated patterned scanning laser for retinal photocoagulatiom. Retina. 2006;26(3):370-6.

10. Kernt M, Cheuteu RE, Cserhati S, Seidensticker F, Liegl RG, Lang J, et al. Pain and accuracy of focal laser treatment for diabetic macular edema using a retinal navigated laser (Navilas). Clin Ophthalmol. 2012;6:289-96

11. Kozak I, Oster SF, Cortes MA, Dowell D, Hartmann K, Kim JS, et al. Clinical evaluation and treatment accuracy in diabetic macular edema using navigated laser photocoagulator NAVILAS. Ophthalmology. 2011;118(6):1119-24.

12. Early photocoagulation for diabetic retinopathy. ETDRS report number 9. Early Treatment Diabetic Retinopathy Study Research Group. Ophthalmology. 1991;98(5 Suppl): 766-88.

13. Friberg TR, Venkatesh S. Alteration of pulse configuration affects the pain response during diode laser photocoagulation. Lasers Surg Med. 1995;16(4):380-3.

14. Photocoagulation for diabetic macular edema. Early Treatment Diabetic Retinopathy Study report number 1. Early Treatment Diabetic Retinopathy Study research group. Arch Ophthalmol. 1985;103(12):1796-806.

15. Photocoagulation for diabetic macular edema. Early Treatment Diabetic Retinopathy Study Report n. 4. The Early Treatment Diabetic Retinopathy Sudy research Group. Int Ophthalmol Clin. 1987;27(4):265-72.

16. Chhablani J, Sambhana S, Mathai A, Gupta V, Arevalo JF, Kozak I. Clinical efficacy of navigated panretinal photocoagulation in proliferative diabetic retinopathy. Am J Ophthalmol. 2015;159(5):884-9.

17. Al-Hussainy S, Dodson PM, Gibson JM. Pain response and follow-up of patients undergoing panretinal laser photocoagulation with reduced exposure times. Eye(Lond). 2008;22(1):96-9. Comment in: Eye (Lond). 2009;23(2):491.

18. Mirshahi A, Lashay A, Roozbahani M, Fard MA, Molaie S, Mireshqhi M, et al. Pain score of patients undergoing single spot, short pulse laser versus conventional laser for diabetic retinopathy. Graefes Arch Clin Exp Ophthalmol. 2013;251(4):1103-7.

19. Schuele G, Rumohr M, Huettmann G, Brinkmann R. RPE damage thresholds and mechanisms for laser exposure in the microsecond-to-millisecond time regimen. Invest Ophthalmol Vis Sci. 2005;46(2):714-9.

20. Mainster M. Decreasing retinal photocoagulation damage: principles and techniques. Semin Ophthalmol. 1999;14(4):200-9.

21. Luttrull JK, Musch DC, Spink CA. Subthreshold diode micropulse panretinal photocoagulation for proliferative diabetic retinopathy. Eye (Lond). 2008;22(5):607-12. Comment in: Eye (Lond). 2009;23(11):2122-3; author reply 2123. 
22. Ober MD, Kernt M, Cortes MA, Kozak I. Time required for navigated macular laser photocoagulation treatment with the Navilas ${ }^{\oplus}$. Graefes Arch Clin Exp Ophthalmol. 2013;251(4):1049-53.

23. Pomerantzeff $O$, Schepens CL. Variation of energy density in argon laser photocoagulation. Arch Ophthalmol. 1975;93(10):1033-5.

24. Chhablani J, Mathai A, Rani P, Gupta V, Arevalo JF, Kozak I. Comparison of conventional pattern and novel navigated panretinal photocoagulation in proliferative diabetic retinopathy. Invest Ophthalmol Vis Sci. 2014;55(6):3432-8.
25. Hoeh AE, Pollithy S, Dithmar S. Factors affecting laser power in retinal Navilas laser treatment. Graefes Arch Clin Exp Ophthalmol 2015;253(6):849-54

26. Fillingim RB. Sex, gender, and pain: women and men really are different. Curr Rev Pain. 2000:4(1):24-30.

27. Diabetic Retinopathy Clinical Research Network; Brucker AJ, Quin H, Antoszyk AN, Beck RW, Bressler NM, Browning DJ, et al. Observational study of the development of diabetic macular edema following panretinal (scatter) photocoagulation Given in 1 or 4 sittings. Arch Ophthalmol. 2009;127(2):132-40. Comment in: Arch Ophthalmol. 2010;128(2):262; author reply 262 